\title{
Оптические и структурные свойства эпитаксиальных слоев $\mathrm{Hg}_{0.7} \mathrm{Cd}_{0.3} \mathrm{Te}$
}

\author{
() Д.А. Андрющенко ${ }^{1}$, М.С. Ружевич ${ }^{1}$, А.М. Смирнов ${ }^{1}$, Н.Л. Баженов ${ }^{2}$, \\ К.Д. Мынбаев ${ }^{2, \uparrow, ~ В . Г . ~ Р е м е с н и к ~}{ }^{3}$ \\ ${ }^{1}$ Университет ИТМО, \\ 197101 Санкт-Петербург, Россия \\ 2 ФТИ им. А.Ф. Иоффе Российской академии наук, \\ 194021 Санкт-Петербург, Россия \\ ${ }^{3}$ Институт фризики полупроводников им. А.В. Ржанова Сибирского отделения Российской академии наук, \\ 630090 Новосибирск, Россия \\ IE-mail: mynkad@mail.ioffe.ru
}

Поступила в Редакцию 31 мая 2021 г.

В окончательной редакции 6 июня 2021 г.

Принята к публикации 6 июня 2021 г.

Приводятся результаты сравнительных исследований оптических и структурных свойств объемных кристаллов и эпитаксиальных пленок $\mathrm{Hg}_{0.7} \mathrm{Cd}_{0.3} \mathrm{Te}$, выращенных различными методами. Данные исследований фотолюминесценции образцов в диапазоне температур $4.2-300 \mathrm{~K}$ показали схожесть их оптических свойств и указывали на существенное разупорядочение твердого раствора. По данным рентгеновской дифракции, однако, масштаб разупорядочения не был напрямую связан со структурным качеством материала. Обсуждены перспективы использования материала, выращенного различными методами, в приложениях оптоэлектроники.

Ключевые слова: $\mathrm{HgCdTe}$, дефекты, люминесценция, рентгеновская дифракция.

DOI: $10.21883 /$ FTP.2021.11.51558.9689

\section{1. Введение}

Твердые растворы $\mathrm{Hg}_{1-x} \mathrm{Cd}_{x} \mathrm{Te}$ (КРТ) являются одним из основных материалов для изготовления приборов и устройств, работающих в инфракрасной (ИК) области спектра. Теллуриды кадмия и ртути образуют непрерывный ряд твердых растворов, на основе которых возможно изготовление приборов фото- и оптоэлектроники, работающих в диапазоне длин волн $\lambda$ от 1 до 14 мкм. В настоящее время растет интерес к КРТ с мольной долей СdTe (химическим составом) $x \approx 0.3$ как материалу для приборов средневолнового $(\lambda=2-6$ мкм) ИК диапазона [1-3]. В этом спектральном диапазоне находятся линии поглощения, обусловленного вращательными и колебательными резонансами молекул многих газов и жидкостей, включая углеводороды, что важно для приложений в области контроля окружающей среды, систем безопасности, энергоаудита, медицины, сельского хозяйства и т. П. [4].

КРТ давно и широко используется при изготовлении фотоприемников [5], однако потенциально рассматривается и как материал для изготовления излучателей [6-8]. Традиционно считалось, что основными проблемами на пути создания излучателей, использующих межзонные оптические переходы в КРТ, являются сложность получения однородного по свойствам материала большой площади и высокая скорость оже-рекомбинации [4]. Развитие технологии КРТ создает предпосылки для преодоления этих ограничений. Так, использование молекулярно-лучевой эпитаксии (МЛЭ) для выращивания
КРТ на подложках $\mathrm{Si}$ уже позволяет получать пластины диаметром до 8 дюймов [9]. Высокие скорости ожерекомбинации в свою очередь могут быть подавлены путем применения квантово-размерных структур [10], а в объемном материале - использованием эффекта локализации экситонов/носителей на флуктуациях состава [11].

Наиболее распространенные в настоящее время методы синтеза КРТ включают МЛЭ, газофазную эпитаксию с использованием металлорганических соединений (МОГФЭ) и жидкофазную эпитаксию (ЖФЭ). Для материала, выращенного каждым методом, характерна определенная дефектная структура, и она может существенно повлиять на параметры изготавливаемых устройств. В настоящей работе представлены результаты сравнительного исследования оптических и структурных свойств эпитаксиальных слоев КРТ с $x \approx 0.3$, выращенных различными методами, с целью анализа перспектив использования этих материалов в различных приборных структурах.

\section{2. Методика эксперимента}

Слои, синтезированные методом МЛЭ, были получены на подложках $\operatorname{GaAs}(013)$ и $\mathrm{Si}(013)$ с буферными слоями ZnTe и CdTe в ИФП им. A.В. Ржанова (Россия) по методике, описанной в работе [12]. Слои, изготовленные методом ЖФЭ, были выращены в закрытой системе из расплавов, обогащенных теллуром, 

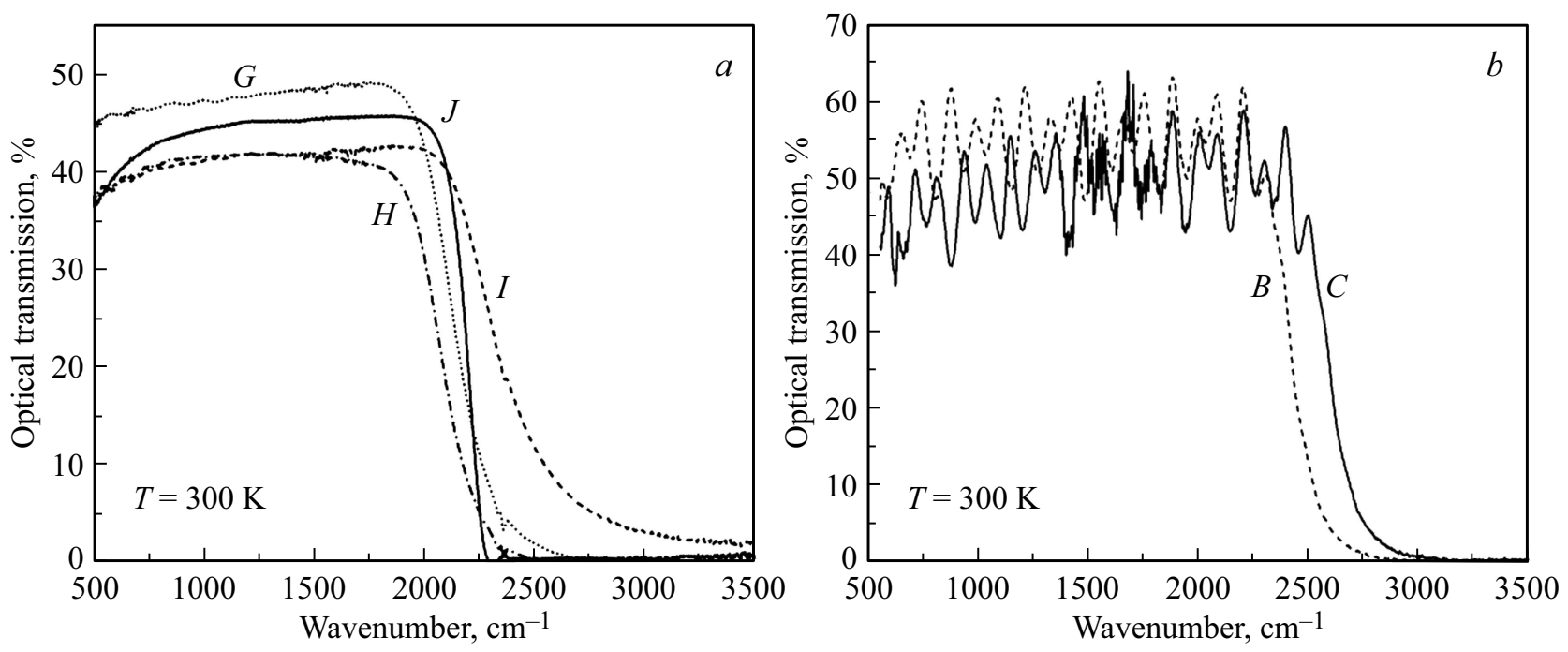

Рис. 1. Спектры оптического пропускания образцов $G, H, I$ и $J(a), B$ и $C(b)$.

на подложках $\mathrm{Cd}(\mathrm{Zn}) \mathrm{Te}(111)$ в соответствии с методикой, представленной в работе [13]. После выращивания эти образцы были отожжены в насыщенных парах $\mathrm{Hg}$ при $230^{\circ} \mathrm{C}$ в течение 48 ч. Для сравнения были также исследованы образцы объемных кристаллов, кристаллы были выращены в АО „Чистые металль“ (Украина) модифицированным методом вертикально направленной кристаллизации (ВНК) с подпиткой из твердой фазы. В исследование были также вовлечены слои, изготовленные методом МОГФЭ; о некоторых их свойствах ранее сообщалось в работе [14]. Они были выращены на полуизолирующих подложках $\mathrm{GaAs}(110)$ с буферным слоем $\mathrm{Cd}(\mathrm{Zn}) \mathrm{Te}$ в компании VIGO System S.A. (Польша) по технологии, аналогичной описанной в работе [3]. Синтез этих структур завершался нанесением тонкого слоя $\mathrm{CdTe}$, в результате чего в процессе охлаждения формировался варизонный поверхностный слой КРТ толщиной до 0.5 мкм. Параметры исследуемых образцов приведены в таблице. Химический состав $x$ и толщина образцов, выращенных методом МЛЭ, были оценены с использованием эллипсометрических изме-

Параметры исследуемых образцов

\begin{tabular}{c|c|c|c|c}
\hline Образец & Метод роста & Подложка & $x$ & $\begin{array}{c}\text { Толщина } \\
\text { пленки, мкм }\end{array}$ \\
\hline$A$ & МЛЭ & $\mathrm{GaAs}$ & 0.30 & 5.0 \\
$B$ & МЛЭ & $\mathrm{GaAs}$ & 0.30 & 8.2 \\
$C$ & МЛЭ & $\mathrm{Si}$ & 0.32 & 8.1 \\
$D$ & МЛЭ & $\mathrm{Si}$ & 0.32 & 8.1 \\
$E$ & МОГФЭ & $\mathrm{GaAs}$ & 0.32 & 10.0 \\
$F$ & МОГФЭ & $\mathrm{GaAs}$ & 0.32 & 9.2 \\
$G$ & ЖФЭ & $\mathrm{CdTe}$ & 0.32 & 16 \\
$H$ & ЖФЭ & $\mathrm{CdZnTe}$ & 0.29 & 20 \\
$I$ & ЖФЭ & $\mathrm{CdTe}$ & 0.30 & 12 \\
$J$ & ВНК & - & 0.30 & -
\end{tabular}

рений in situ [12] и исследований оптического пропускания (ОП). Для слоев, выращенных методами ЖФЭ и МОГФЭ, а также образцов объемных кристаллов, эти параметры оценивались по спектрам ОП и данным оптической микроскопии.

Спектры ОП записывались при температуре $T=300 \mathrm{~K} \quad$ с использованием фурье-спектрометров InfraLum-801 и ФСM2203. Спектры фотолюминесценции (ФЛ) записывались в интервале температур $4.2-300 \mathrm{~K}$ с использованием решеточного монохроматора МДР-23. Сигнал ФЛ возбуждался полупроводниковым лазером с длиной волны 1.03 мкм и регистрировался фотоприемником $\mathrm{InSb}$ или $\mathrm{HgCdTe}$. Для структурных исследований использовался рентгеновский дифрактометр ДРОН-8 в щелевой конфигурации с тонкофокусной рентгеновской трубкой с медным анодом и сцинтилляционным детектором $\mathrm{NaI}(\mathrm{Tl})$.

\section{3. Результаты и обсуждение}

На рис. 1 приведены спектры ОП ряда исследованных образцов. Как видно, они характеризуются относительно резкими краями пропускания; наиболее резкий край ОП был характерен для образца объемного кристалла (рис. $1, a$, образец $J$ ), наклон кривых ОП в области межзонного поглощения для всех эпитаксиальных слоев был близким. Положение края ОП для слоев, выращенных МЛЭ (рис. $1, b$ ), соответствовало значениям химического состава, определенным по данным эллипсометрии. Для этих образцов имели место характерные интерференционные полосы при малых волновых числах.

На рис. 2 показаны нормализованные спектры ФЛ образцов $A, B, C$ и $D$ (рис. 2, $a$ ), и $E$ (из работы [14]), $H$ и $J$ (рис. $2, b$ ), записанные при $85 \mathrm{~K}$. Полная ширина на полувысоте (полуширина) спектров, записанных при этой температуре, составляла 14.8 мэВ для образца $A$, 

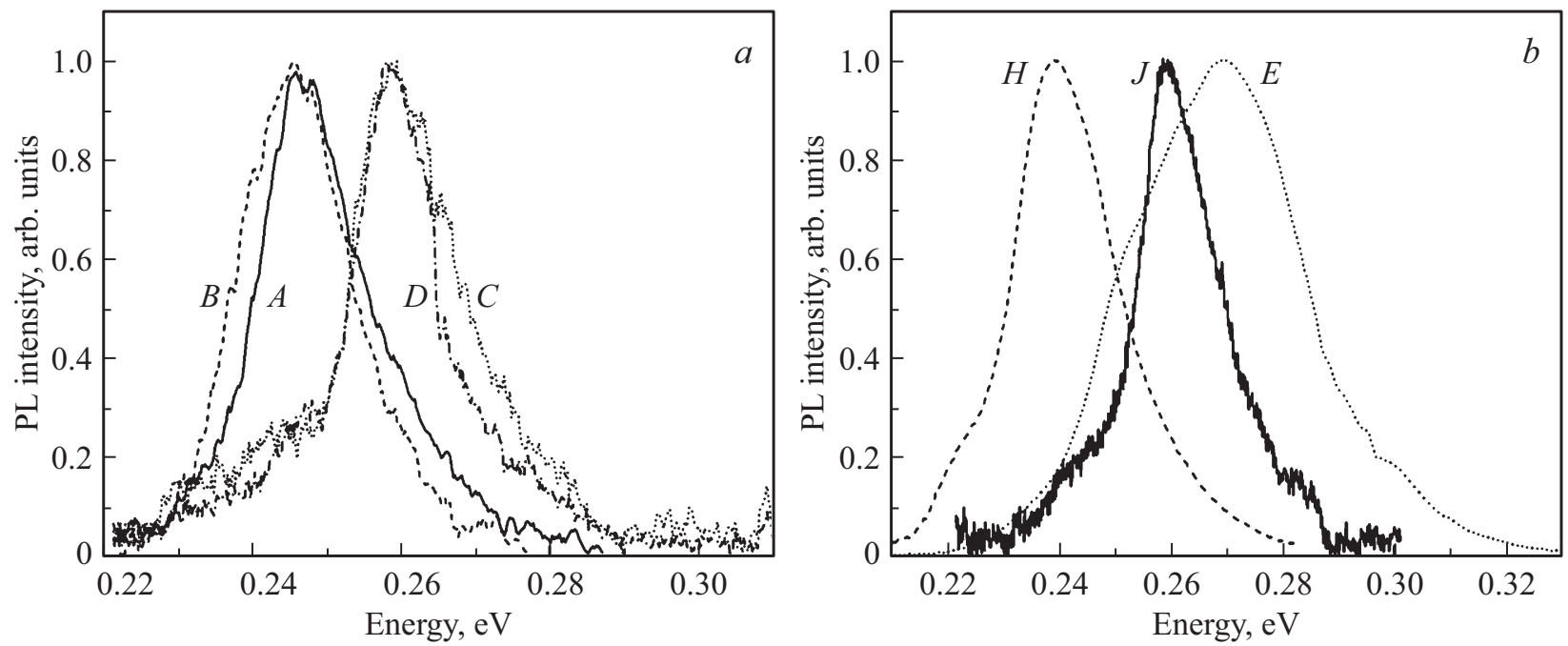

Рис. 2. Спектры фотолюминесценции образцов $A, B, C$ и $D(a), E, H$ и $J(b)$, записанные при температуре $85 \mathrm{~K}$. Различия в уровне шумов на спектрах обусловлены различиями в интенсивности сигналов ФЛ и в условиях записи спектров.

15.0 мэВ для образцов $B$ и $C, 12.6$ мэВ для образца $D$, 17.2 мэВ для образца $I, 15.7$ мэВ для образцов $J$ и $K$ и 19.4 мэВ для образца $H$. Спектры образцов $E$ и $F$, выращенных методом МОГФЭ, были существенно шире, их полуширины при $85 \mathrm{~K}$ составили соответственно 31 и 28 мэВ. Это могло быть обусловлено тем, что твердый раствор в данном случае формировался за счет взаимной диффузии компонентов соединений $\mathrm{CdTe}$ и $\mathrm{HgTe}$, наносившихся в ходе эпитаксии тонкими слоями послойно [3], что могло способствовать некоторой неоднородности эпитаксиального слоя по составу по его толщине. При $T=4.2 \mathrm{~K}$ полуширина спектров ФЛ составила 7.3 мэВ для образца $C, 6.5$ мэВ для образца $D$ и 16.2 мэВ для образца $E$.

На рис. 3 приведены примеры температурных зависимостей положений максимумов полос ФЛ $E_{\mathrm{PL}}(T)$ для некоторых образцов (символы), а также зависимость ширины запрещенной зоны $E_{g}(T)$, рассчитанная для КРТ с $x=0.32$ в соответствии с эмпирическим соотношением $E_{g}(x, T)$ из работы [15] (сплошная кривая). Как видно, экспериментальные зависимости имеют близкий наклон, и он отличается от наклона расчетной зависимости $E_{g}(T)$. Это отличие наблюдалось для всех исследованных образцов и было связано с тем, что оптические переходы в КРТ при низких температурах вызваны рекомбинацией экситонов, локализованных на флуктуациях состава [16-19]; при этом известно, что для слоев КРТ, выращенных ЖФЭ, различие между $E_{\mathrm{PL}}$ и $E_{g}$ при низких температурах существенно меньше, чем для слоев, полученных методом МЛЭ [20]. Поведение $E_{\mathrm{PL}}(T)$ для образца $E$ могло быть связано с наличием варизонного поверхностного слоя или с указанной выше неоднородностью по составу и требует дальнейших исследований. Для образцов $E$ и $F$ при $T=85 \mathrm{~K}$ были записаны спектры фотопроводимости (для образца $E$ спектр приведен в работе [14]). Положение полуспада

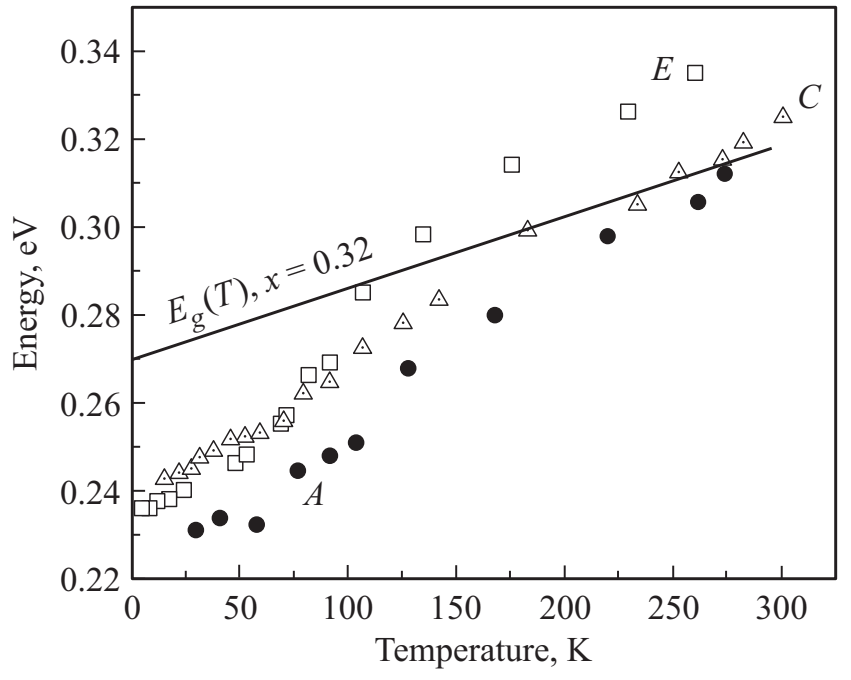

Рис. 3. Температурные зависимости положений максимумов полос ФЛ для образцов $A, C$ и $E$ (символы) и зависимость $E_{g}(T)$ для КРТ с $x=0.32$ согласно данным работы [15] (сплошная кривая).

длинноволновой границы фотопроводимости для обоих образцов соответствовало энергии $\sim 0.28 \mathrm{\jmath}$, что, согласно использованной зависимости $E_{g}(x, T)$, соответствовало заявленному составу пленки.

На рис. 4, $a$ показана дифрактограмма образца объемного кристалла КРТ (образец $J$ ). Она содержит единственный пик при $2 \theta \approx 23.79^{\circ}$, соответствующий кристаллографической плоскости $\mathrm{HgCdTe}(111)$. Малая интенсивность данного пика свидетельствует об относительно низком кристаллическом совершенстве образца; это подтверждается отсутствием отражений от плоскостей (222) и (444), которые наблюдались нами в аналогичных условиях для объемного кристалла КРТ с 

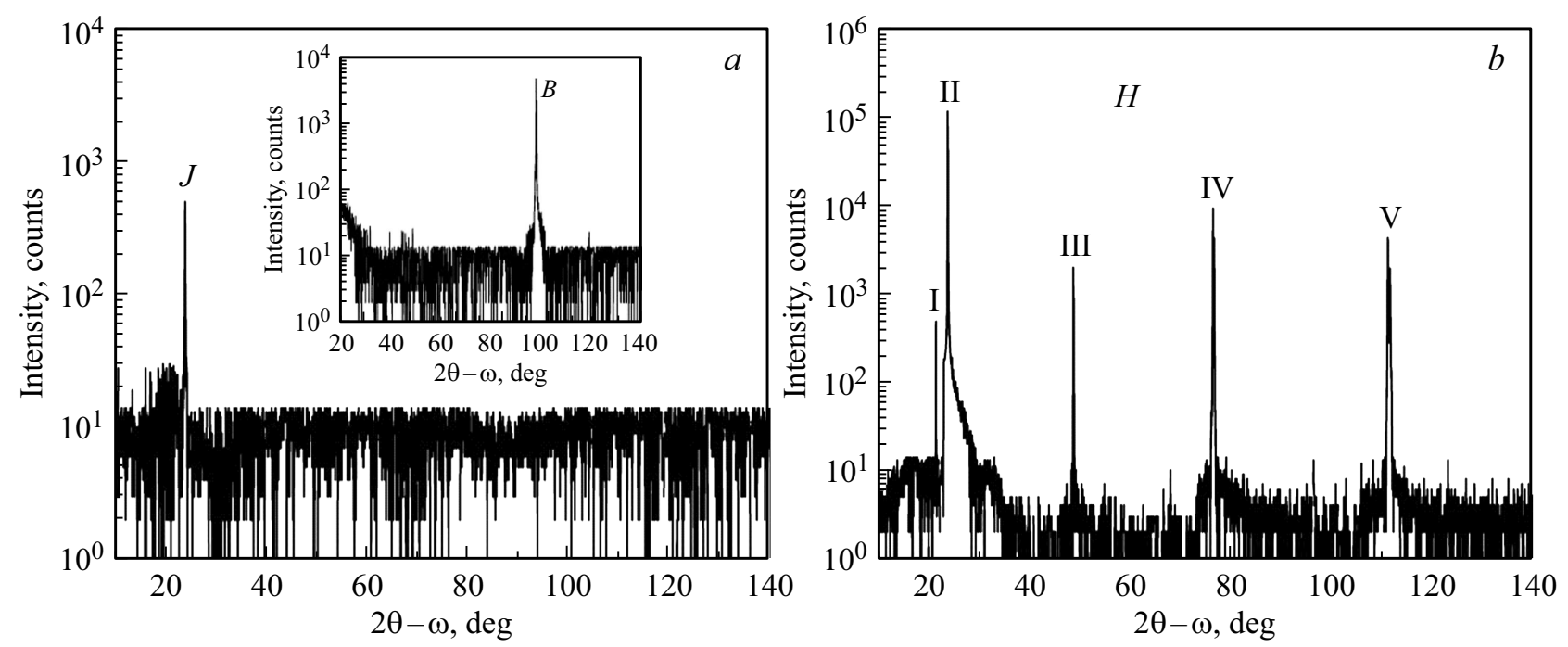

Pис. 4. Дифрактограммы образцов $J$ (на вставке - образца $B)(a)$ и $H(b)$.

$x \approx 0.7$ [21]. Кривая качания рентгеновской дифракции (РД) данного образца (не показана) свидетельствовала о присутствии множественных единичных блоков с ориентацией (111), разориентированных относительно друг друга; ее полуширина составила $0.9^{\circ}$ (для монокристалла с $x \approx 0.7$, рассмотренного в работе [21], она составляла $\left.0.4^{\circ}\right)$.

Дифрактограммы слоев, выращенных методом ЖФЭ, содержали пять пиков. На рис. 4, $b$ показана дифрактограмма для образца $H$. Первый пик (пик $I$ ) при $2 \theta \approx 21.52^{\circ}$, в отличие от остальных, не разделялся на $K_{\alpha 1}$ и $K_{\alpha 2} ;$ возможно, как и в случае с кристаллом с $x \approx 0.7$ [21], его присутствие носило сопутствующий характер, и было вызвано окислением поверхности образца. Пик II при $2 \theta \approx 23.84^{\circ}$ соответствовал плоскости $\mathrm{HgCdTe}(111)$. Также присутствовали дальние порядки отражений от плоскости (111): плоскости (222) (пик III при $\left.2 \theta \approx 48.77^{\circ}\right)$ и $(444)$ (пик $\mathrm{V}$ при $2 \theta \approx 111.25^{\circ}$ ), однако интенсивность отраженного пучка от плоскости (222) была ниже, чем от плоскости (444). Кроме того, на дифрактограмме присутствовало отражение от плоскости (511) (пик IV при $2 \theta \approx 76.51^{\circ}$ ). В целом обе пленки, выращенные методом ЖФЭ, обладали поликристаллической структурой с блоками с ориентацией [111] и [511] и высоким кристаллическим совершенством отдельных блоков. Значения полуширин кривых качания РД для этих пленок находились в интервале $100-150^{\prime \prime}$.

Дифрактограммы образцов $B$ и $C$ (на вставке к pис. 4, $a$ показана дифрактограмма для образца $B$ ) были аналогичными таковым для пленок с составами $x \approx 0.7$ и $x \approx 0.4$, рассмотренных в работах $[21,22]$. Здесь доминировал пик при $2 \theta \approx 97.8^{\circ}$, типичный для дифрактограмм МЛЭ КРТ [22]. Полуширина этого пика для образца $B$ составила $3236^{\prime \prime}\left(2 \theta \approx 97.81^{\circ}\right)$, для образца $C-1038^{\prime \prime}\left(2 \theta \approx 97.76^{\circ}\right)$. Набор пиков при $25-36^{\circ}$ был, скорее всего, связан с наложением множественных пиков от отдельных слоев, составляющих гетероэпитаксиальную структуру [21].

Таким образом, по данным РД, наиболее высокое кристаллическое качество среди исследованных образцов было у слоев, выращенных методом ЖФЭ. Резкий край ОП и относительно малая полуширина пика ФЛ при $85 \mathrm{~K}$, характерные для исследованных образцов объемных кристаллов КРТ, не коррелировали с относительно низким (согласно результатам РД) кристаллическим совершенством. Слои КРТ с $x \approx 0.3$, выращенные методом МЛЭ, несмотря на неоднозначные результаты исследований РД, показали малые значения полуширин низкотемпературных спектров ФЛ и отсутствие оптических переходов с участием состояний, связанных с неконтролируемыми примесями, характерных для аналогичных слоев бо́льших составов [19]. Также из всех исследованных образцов только слои, выращенные методами МЛЭ и МОГФЭ, продемонстрировали сигнал ФЛ при $T>150 \mathrm{~K}$. Это можно объяснить наличием в них масштабных „технологических“ флуктуаций состава в дополнение к стохастическим флуктуациям; эти флуктуации способствуют более сильной локализации экситонов $[11,19]$. Таким образом, именно этот материал, очевидно, наиболее перспективен для изготовления излучателей средневолнового ИК диапазона на основе КРТ.

\section{4. Заключение}

В работе были проведены исследования оптических и структурных свойств объемных кристаллов и эпитаксиальных пленок $\mathrm{Hg}_{0.7} \mathrm{Cd}_{0.3} \mathrm{Te}$, выращенных различными методами. Вид и полуширина (от $\sim 13$ до $\sim 20$ мэВ при $85 \mathrm{~K}$ ) спектров фотолюминесценции всех образцов были схожими. Температурные зависимости положения максимума пика люминесценции указывали на разупоря- 
дочение твердого раствора. Можно отметить, что по данным рентгеновской дифракции масштаб данного разупорядочения не был напрямую связан со структурным качеством материала, поэтому его природа и влияние на свойства, отличные от оптических (транспорт и т. п.), требуют дальнейших исследований.

\section{Благодарности}

Авторы благодарят Н.Н. Михайлова, М.В. Якушева и В.С. Варавина за предоставление образцов, выращенных методом МЛЭ, М.А. Ременного - за помощь в проведении измерений оптического пропускания.

\section{Конфликт интересов}

Авторы заявляют, что у них нет конфликта интересов.

\section{Список литературы}

[1] F.Y. Yue, S.Y. Ma, J. Hong, P.X. Yang, C.B. Jing, Y. Chen, J.H. Chu. Chin. Phys. B, 28, 017104 (2019).

[2] X.F. Qiu, S.X. Zhang, J. Zhang, Y.C. Zhu, C. Dou, S.C. Han, Y. Wu, P.P. Chen. Crystals, 11, 296 (2021).

[3] M. Kopytko, J. Sobieski, W. Gawron, A. Kebłowski, J. Piotrowski. Semicond. Sci. Technol., 36, 055003 (2021).

[4] D. Jung, S. Bank, M.L. Lee, D. Wasserman. J. Opt., 19, 123001 (2017)

[5] W. Lei, J. Antoszewski, L. Faraone. Appl. Phys. Rev., 2, 041303 (2015)

[6] C.R. Tonheim, A.S. Sudbø, E. Selvig, R. Haakenaasen. IEEE Photon. Technol. Lett., 23, 36 (2011).

[7] J.P. Zanatta, F. Noël, P. Ballet, N. Hdadach, A. Million, G. Destefanis, E. Mottin, C. Kopp, E. Picard, E. Hadji. J. Electron. Mater., 32, 602 (2003).

[8] E. Hadji, E. Picard, C. Roux, E. Molva, P. Ferret. Optics Lett., 25, 725 (2000).

[9] M. Reddy, X. Jin, D.D. Lofgreen, J.A. Franklin, J.M. Peterson, T. Vang, N. Juanko, F. Torres, K. Doyle, A. Hampp, S.M. Johnson, J.W. Bangs. J. Electron. Mater., 48, 6040 (2019).

[10] V.Ya. Aleshkin, V.V. Rumyantsev, K.E. Kudryavtsev, A.A. Dubinov, V.V. Utochkin, M.A. Fadeev, G. Alymov, N.N. Mikhailov, S.A. Dvoretsky, F. Teppe, V.I. Gavrilenko, S.V. Morozov. J. Appl. Phys., 129, 133106 (2021).

[11] А.В. Шиляев, К.Д. Мынбаев, Н.Л. Баженов, А.А. Грешнов. ЖТФ, 87, 419 (2017).

[12] Ю.Г. Сидоров, В.С. Варавин, С.А. Дворецкий, Н.Н. Михайлов, М.В. Якушев, И.В. Сабинина. ФТП, 35, 1092 (2001).

[13] K.E. Mironov, V.K. Ogorodnikov, V.D. Rozumnyi, V.I. IvanovOmskii. Phys. Status Solidi A, 78, 125 (1983).

[14] И.И. Ижнин, А.И. Ижнин, Е.И. Фицыч, J. Piotrowski, К.Д. Мынбаев. Изв. вузов. Физика, № 9/2, 89 (2013).

[15] C.R. Becker, V. Latussek, A. Pfeuer-Jeschke, G. Landwehr, L.W. Molenkamp. Phys. Rev. B, 62, 10353 (2000).

[16] R. Legros, R. Triboulet. J. Cryst. Growth, 72, 264 (1985).

[17] P. Gille, K.H. Herrmann, N. Puhlmann, M. Schenk, J.W. Tomm, L. Werner. J. Cryst. Growth, 86, 593 (1988).

[18] A. Lusson, F. Fuchs, Y. Marfaing. J. Cryst. Growth, 101, 673 (1990).
[19] К.Д. Мынбаев, Н.Л. Баженов, В.И. Иванов-Омский, Н.Н. Михайлов, М.В. Якушев, А.В. Сорочкин, В.Г. Ремесник, С.А. Дворецкий, В.С. Варавин, Ю.Г. Сидоров. ФТП, 45, 900 (2011).

[20] I.I. Izhnin, A.I. Izhnin, K.D. Mynbaev, N.L. Bazhenov, A.V. Shilyaev, N.N. Mikhailov, V.S. Varavin, S.A. Dvoretsky, O.I. Fitsych, A.V. Voitsekhovsky. Opto-Electron. Rev., 21, 390 (2013).

[21] К.Д. Мынбаев, Н.Л. Баженов, А.М. Смирнов, Н.Н. Михайлов, В.Г. Ремесник, М.В. Якушев. ФТП, 54, 1302 (2020).

[22] D.A. Andryushchenko, I.N. Trapeznikova, N.L. Bazhenov, M.A. Yagovkina, K.D. Mynbaev, V.G. Remesnik, V.S. Varavin. J. Phys. Conf. Ser., 1400, 066038 (2019).

Редактор А.Н. Смирнов

\section{Optical and Structural Properties of $\mathrm{Hg}_{0.7} \mathbf{C d}_{0.3}$ Te Epitaxial Films}

\author{
D.A. Andryushchenko' ${ }^{1}$, M.S. Ruzhevich', \\ A.M. Smirnov ${ }^{1}$, N.L. Bazhenov ${ }^{2}$, \\ K.D. Mynbaev ${ }^{2}$, V.G. Remesnik ${ }^{3}$ \\ 1 ITMO University, \\ 197101 St. Petersburg, Russia \\ 2 loffe Institute, \\ 194021 St. Petersburg, Russia \\ ${ }^{3}$ Rzhanov Institute of Semiconductor Physics, \\ Siberian Branch of Russian Academy of Sciences, \\ 630090 Novosibirsk, Russia
}

Abstract The results of comparative studies of the optical and structural properties of $\mathrm{Hg}_{0.7} \mathrm{Cd}_{0.3} \mathrm{Te}$ bulk crystals and epitaxial films grown by various methods are presented. The data of photoluminescence studies performed in the temperature range $4.2-300 \mathrm{~K}$ showed the similarity of the optical properties of different samples and indicated a significant disordering of the solid solution. According to $X$-ray diffraction data, however, the scale of the disordering was not directly related to the structural quality of the material. The prospects for using the material grown by various methods in optoelectronics applications are discussed. 